\title{
Energy and resources cooperation for greenhouse gases emissions reduction of industrial sector
}

\begin{abstract}
Energy and resources cooperation has a great potential of reducing greenhouse gases (GHG) emissions of companies, especially in industrial and business parks where facilities are located in geographical proximity. Such cooperation could cut emissions without significant impact on profit, and in some cases, may even reduce costs by decreasing waste generation and improving energy efficiency. This paper combines similar themes of industrial symbiosis, sharing economy and circular economy to formulate a single robust concept of energy and resources cooperation. A framework and methodology for mass implementation of energy and resources cooperation is proposed by integrating disparate fields of industrial ecology, business studies and industrial investments. Furthermore, an approach of enhancing such cooperation is proposed which involves an establishment of a specialized Cooperation Development and Management Company. Finally, research agenda is set out to capitalise the developments of industry 4.0 and peer to peer sharing for energy and resources cooperation.
\end{abstract}

Keywords: Energy and resources cooperation; Industrial symbiosis; Cooperation framework; peer to peer sharing; Cooperation Development and Management Company; Eco industrial parks

\section{Introduction}

Global industrial greenhouse gas (GHG) emissions are increasing every year ${ }^{1}$ which underscores the need for exploring new approaches to reduce emissions. Emissions reduction from the industrial sectors and particularly industrial parks could play a significant role in cutting industrial GHG emissions as the parks' emissions can constitute a significant portion of total emissions from industrial sector ${ }^{2}$. The IPCC (2014) ${ }^{3}$ identified that clustering of businesses in proximity can facilitate growth and competitiveness and present opportunities for emission mitigation through shared infrastructure and purchasing. Energy and resources cooperation are one such approach that can be utilized by businesses and industries in geographical proximities to reduce GHG emissions. The term "energy and resources cooperation" used in this paper is defined later (Section 3.2.1), but in a broad sense describes any transaction or sharing of energy and resources among businesses, with the aim to reduce GHG emissions by improving energy efficiency or decreasing waste production. Thus, energy and resources cooperation also include similar concepts such as sharing economy ${ }^{4}$, industrial symbiosis ${ }^{5}$ and circular economy ${ }^{6}$.

The need for a systematic approach to understand the dynamics of industrial symbiosis relationships has been highlighted ${ }^{3,7,8}$ as this is an under-studied topic. Additionally, it is important to explore methods to establish and enhance the mass implementation of energy and resources cooperation. This is mainly because mass implementation of cooperation projects improves the prospects for upscaling and it has been argued that businesses show greater interest in economy of scale rather than cooperating for environmental sustainability 9 . In this context, there is a great necessity to develop a robust framework that facilitates mass adoption and implementation of effective energy and resources cooperation.

This paper combines the disparate but related concepts of industrial symbiosis, circular economy, peer to peer transaction and sharing economy to formulate a single and comprehensive concept of energy and resources cooperation. We develop and propose a novel systematic framework to facilitate establishment and mass implementation of interfirm cooperation projects. This paper also highlights the potential of utilising industry 4.0 and peer to peer transactions to enhance energy and resources 
cooperation and calls for research in this topic. A methodology to establish an understanding of the requirements of these concepts is presented and explained (Section 2). Subsequently, existing practices in industrial symbiosis, eco-industrial parks and peer to peer sharing are analysed to define a unified concept of energy and resources cooperation and identify salient features of the cooperation (Section 3). Based on the identified features, the cooperation framework is developed to help facilitate mass uptake of cooperation projects (Section 4). To enhance the cooperation the establishment of a specialised company is proposed and discussed (Section 5). We conclude with recommendations and a suggested research agenda for energy and resources cooperation (Section 6). The knowledge and framework developed in this paper offers an important contribution to enhance energy and resources cooperation and contribute towards collaboration for GHG emissions mitigation.

\section{Methodology}

The framework for energy and resources cooperation developed in this paper is guided by the authors' attempt to tackle the following research questions. Firstly, how can cooperation between companies/industries be enhanced to reduce negative environmental impacts? Second, what are the key factors affecting the implementation of such cooperation? Thirdly, what are the key stages required to establish a cooperation?

A literature review was conducted aiming to identify relevant literature published during the past two decades on best practice in the establishment and operation of energy and resource cooperation in business parks to improve environmental impact. The literature review included searches of published peer-reviewed research through various academic search providers (e.g. Google Scholar, BASE, Science.gov, SemanticScholar), using the keywords "energy cooperation", "industrial symbiosis", "circular economy", "peer-to-peer" in combination with "industry", "industrial", "energy", "business park(s)" and/or "resources". Studies were screened on topic relevance in order to develop a detailed understanding of existing key salient features of existing or proposed cooperation schemes.

In addition to the literature review, four focus group discussions were conducted with companies located at seaports in the UK, France, Netherlands and Belgium. The focus groups were conducted as a part of Port Energy and Carbon Savings ${ }^{10}$ Project funded by the European Union, under the Interreg Two Seas programme. One of the aims of this project is to develop an effective approach to establish cooperation among port companies to reduce GHG emissions. The framework on energy and resources cooperation developed here and the findings of this paper are therefore based on empirical analysis of industries that participated in the Port Energy and Carbon Savings Project.

\section{Results}

In this section, the outcomes of the literature review and focus groups are summarised to present the salient features of energy and resources cooperation. Over forty relevant and representative studies were identified in the literature (Table 1). In geographical terms, the majority of the studies are from Europe and Asia - mostly China. Overall this geographical distribution reflects the development and spread of industrial symbiosis over recent decades. The authors' aim is to identify key features of similar themes such as industrial symbiosis, eco-industrial parks, circular economy et cetera to unite them under a single concept of energy and resources cooperation rather than conducting a comprehensive review of the literature. The focus groups further supplemented the information gathered in the literature review highlighting existing approaches, practice, features, and potential barriers. 
Table 1: Summary of findings from literature review

\begin{tabular}{|c|c|}
\hline Paper & Themes \\
\hline $\begin{array}{l}\text { Zhang et al }{ }^{11}, 2020 ; \text { Jacobsen, } \\
2006^{12} ; \text { Mirata, 2004 }{ }^{13} \text {; Zhe et } \\
\text { al }{ }^{14}, 2016 ; \text { Chertow, 2007 } ; \text {;u } \\
\text { et al }\left.\right|^{16}, 2015\end{array}$ & $\begin{array}{l}\text { Benefits of industrial symbiosis; case studies of best practice and } \\
\text { success; 'uncovering' of existing symbioses as an approach to build } \\
\text { eco-industrial parks; economic benefits as drivers for stakeholders } \\
\text { involvement }\end{array}$ \\
\hline $\begin{array}{l}\text { Ramsheva et al }{ }^{17}, 2019 ; \text { Aston } \\
\& \text { Bain }^{18}, 2001 ; \text { Doménech \& } \\
\text { Davies }{ }^{19}, 2011 ; \text { Paquin \& } \\
\text { Howard-Grenville }^{20}, 2012 ; \\
\text { Jensen et al }{ }^{21}, 2011 ; \\
\text { Mallawaarachchi et al }\left.\right|^{22}, 2020 ; \\
\text { Boons et al }{ }^{23}, 2011 \\
\end{array}$ & $\begin{array}{l}\text { Social characteristics, including social network structure, } \\
\text { communication, and similarities in norms, trust, openness and } \\
\text { communication in industrial symbiosis. }\end{array}$ \\
\hline 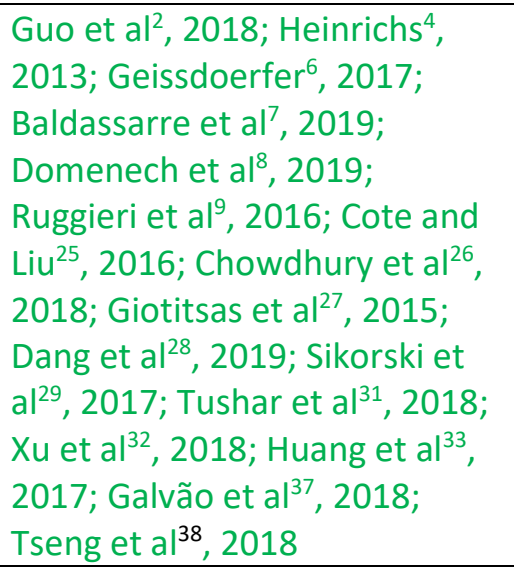 & $\begin{array}{l}\text { Potential of peer-to-peer approach, sharing economy, circular } \\
\text { economy and industrial parks in reducing GHG emissions; application } \\
\text { of blockchain; Industry 4.0; need to study industrial symbiosis from } \\
\text { perspectives of circular economy and industrial ecology; contribution } \\
\text { of industrial symbiosis to circular economics. }\end{array}$ \\
\hline $\begin{array}{l}\text { Chertow et al }\left.\right|^{5}, 2012 \text {; Liu et } \\
\text { al }^{24}, 2018 ; \text { Bacudio et }^{34} \\
\text { 2016; Golev et }{ }^{35}, 2014 ; \\
\text { Tsvetkova et } \mathrm{al}^{36}, 2012\end{array}$ & $\begin{array}{l}\text { Analysis of industrial symbiosis as self-organising complex system; } \\
\text { Analysis of eco-industrial parks using energy as an indicator; non- } \\
\text { technical barriers such as lack of cooperation and trust for } \\
\text { implementing industrial symbiosis; buy-in from top management } \\
\text { required to remove barriers for industrial symbiosis; Modular } \\
\text { approach for industrial symbiosis. }\end{array}$ \\
\hline $\begin{array}{l}\text { Freitag et al }{ }^{39}, 2015 ; \text { Yazan and } \\
\text { Fraccascia }^{40}, 2020 .\end{array}$ & $\begin{array}{l}\text { Simulation model for resource sharing; input-output model and } \\
\text { agent-agent based simulation for industrial symbiosis. }\end{array}$ \\
\hline $\begin{array}{l}\text { Tao et al }\left.\right|^{41}, 2019 ; \text { International } \\
\text { Synergies }{ }^{42}, 2020 ; \text { European } \\
\text { Cluster Collaboration } \\
\text { Programme } 43,2018 ; \text { Patala et } \\
\text { al }^{44}, 2020 ; \text { Hampl }^{45}, 2019 ; \\
\text { Evans et }^{146}, 2017\end{array}$ & $\begin{array}{l}\text { Need to explore policies that foster industrial symbiosis from firms' } \\
\text { perspectives; need to explore policy options that allow switching } \\
\text { partners for energy and resources cooperation; government entities } \\
\text { to support energy and resources cooperation; role of intermediaries } \\
\text { in supporting cooperation; Library of existing industrial symbiosis } \\
\text { projects. }\end{array}$ \\
\hline
\end{tabular}

\subsection{Existing approaches and practices}

There are several industrial parks ${ }^{5}$ that share energy and resources based on industrial symbiosis such as parks in Kalundborg, Denmark; Guayama, Puerto Rico; and Kwinana, Australia. Broadly, Industrial symbiosis is about the development and operation of interfirm resource exchanges ${ }^{5}$ and thus is also energy and resources cooperation. Establishment of eco-industrial parks ${ }^{24,25}$ is one method to enable industrial symbiosis that specifically focuses on environmental issues. These parks are different from conventional business or industrial parks as they promote maximizing the use of renewable energy 
technologies, foster circular economy and encourage symbiosis among park tenants to reduce waste and improve efficiency. Tenants producing their own electricity through renewable energy sources has been recommended ${ }^{25}$ as a strategy to reduce GHG emissions of eco-industrial parks.

Utilizing a support of a typically third-party company known as Energy Service Company (ESCO) is another approach to enable interfirm projects that share or trade energy and resources. Several previously identified areas of ESCO support ${ }^{26}$ that are applicable for energy and resources cooperation are aspects of interfirm projects such as engineering-procurement-construction, build- operatetransfer, and energy performance and service contracting. Other approaches to implement energy and resources cooperation are through sharing economy enabled by peer to peer (P2P) network, industry 4.0 and energy cooperatives.

P2P network is a network where members (peers) share information and part of their hardware or software in order to enable certain application ${ }^{27}$ or transaction, which in the case of energy and resources cooperation would be any action related to sharing or trading of energy or resources. Companies like Airbnb and Uber are generic examples of sharing economy enabled by P2P model. Suitability of P2P model for energy and resources cooperation has been shown for electricity trading for industries ${ }^{28,29}$ as well as a community electricity microgrid ${ }^{30}$. Tools used for P2P model include blockchain $^{28,29,30}$ and signal processing techniques such as game theory ${ }^{31}$. It may be noted that we are using the broad term P2P to also refer to business to business (B2B) model and virtual power plants in this paper.

The potential of energy and resources cooperation is also very high in industry 4.0 model. Viewed as fourth industrial revolution, industry 4.0 has components such as cyber-physical systems, Internet of Things (IOT) and cloud computing ${ }^{32}$. A concept of community energy system ${ }^{33}$ has been presented which envisions energy and resources sharing between local communities and industries that is enabled by the principles of industry 4.0. Information exchange platform will facilitate trading of energy and resources between communities and industries in this approach.

\subsection{Salient features}

Based on analysis of wide-ranging approaches and practices adopted for energy and resources cooperation, main salient features of energy and resources cooperation are identified in this section. This paper limits its focus on the types of cooperation that aim at reducing negative environmental impacts rather than those solely motivated by profits. The main salient features are presented below.

\subsubsection{Common infrastructure or recovery of resource and energy}

In order to clearly differentiate between regular business transactions and energy and resources cooperation, it is necessary to set a minimum condition that defines energy and resources cooperation. This salient feature sets the minimum condition by defining energy and resources cooperation as fulfilment of either of the following two criteria: a) utilisation of common infrastructure by more than one business enterprise where the infrastructure could be physical hardware or software, or b) resource and energy recovery where by-product or waste of at least one industry is utilised by another industry (or other industries). An example of the former could be two companies in an eco-industrial park sharing a common solar PV system for electricity. Likewise, an example of latter could be an incineration/bioenergy plant using manure or other bio-waste from a farming industry as fuel to produce electricity. This leads to recovery of waste (manure) of one company (farming industry in this case) which is then used as resource by another company (incineration plant in this case). 


\subsubsection{Trust and security}

There exists a certain level of trust among companies that participate in energy and resources cooperation and potential lack of trust has been identified as one of the biggest barriers to interfirm cooperation ${ }^{34,35}$. Cooperation cannot happen if companies do not trust one another, especially if the companies are in competition with each other. Likewise, perception of security by participating companies in the interfirm transaction engendered by the cooperation is another feature of energy and resources cooperation. This is particularly important when one company relies on resource supply from another company. For example, cooperation between an incinerator company and a farming company may lead to a situation where the incinerator company relies on waste/manure supply from the farming company for energy production. In this case, the incinerator company should have a sense of assurance on reliability of waste/manure supply from the farming company.

\subsubsection{Robust communication and coordination}

Effective communication and information sharing among participating companies is another salient feature of energy and resources cooperation. Robust communication and coordination strategy are required not only during the initial project planning and establishment phase but also throughout the project life cycle. Lack of proper communication and unwillingness to share relevant information has been identified as a major barrier for industrial symbiosis ${ }^{35}$ and can also reduce trust. In addition to human level interaction, coordination and communication between infrastructures may also be advantageous, especially when interfirm sharing of infrastructure occurs as a part of cooperation scheme. With the advent of IOT, industry 4.0 and peer to peer sharing, such coordination and communication can be greatly enhanced which brings new opportunities for energy and resources cooperation.

\subsubsection{Project feasibility}

The projects envisioned for energy and resources cooperation should be feasible both technically and economically. Although companies may participate on a commercially loss-making cooperation project as a part of their corporate social responsibility, such project is unlikely to be sustainable. Therefore, project feasibility must be ensured. While energy and resources cooperation projects do not have to be financially attractive, they should not be loss making ventures and should have net present values equal or greater than zero.

\section{Cooperation framework}

Based on the key features identified in previous sections, a framework methodology to establish an energy and resources cooperation are developed to facilitate mass uptake of cooperation schemes. Figure 1 presents the framework that shows overall lifecycle and interactions among various factors of energy and resources cooperation.

The cooperation starts with project conceptualization where potential projects and stakeholders are identified and short listed. The identified projects should meet the minimum condition set to define energy and resources cooperation (see Section 3.2.1). As shown in Figure 1, project feasibility is the next phase after project conceptualization. The feasibility should ensure that the project is viable from every aspect including, technical, financial, legal, institutional and social. Once the project feasibility is ensured, project execution mechanism should be designed. This should determine the mechanism for building, operating, and maintaining the project. The participating companies could build and operate the cooperation project on their own or they could hire a third party ESCO for this purpose. Likewise, roles and responsibilities of all participating companies should be determined in this phase. 
The project execution design should also contain the financial model which describes a) how the project will be financed, and, b) how the profit (if any) of the project will be shared.

Trust among participating companies is an important feature of energy and resources cooperation (see Section 3.2.2) and therefore security and risk management should be done in parallel with project execution design (Figure 1). The purpose of the security and risk management is to ensure that each participating company fulfils its roles and responsibilities. The risk management plan is needed to plan for a situation where any of the participating companies fail to comply with their commitment. Legal contract among participating companies to ensure that all companies fulfil their responsibilities and reasonable compensation in case of failure to comply could be a part security and risk management. Thus, security and risk management will increase trust. Finally, after all the planning and feasibility studies are done, the energy and resources cooperation project can be implemented.

It is also necessary to evaluate the cooperation project after few years of its completion to determine whether the project has been successful. The degree of success can be measured based on the following factors: a) environmental benefits created by the project, b) project sustainability, and c) profit or saving generated by the project. The environmental benefits generated by the project and its degree of success determined during monitoring and evaluation phase is crucial to provide evidencebased policy decision. Furthermore, the results from monitoring and evaluation will also aid in conceptualization of future energy and resources cooperation projects.

The importance of proper coordination among three disparate areas of industrial ecology, business studies and industrial investments has been known $^{36}$ in order to establish robust energy and resources cooperation. The framework (Figure 1) presented in this paper integrates all these three areas among others to facilitate mass uptake of energy and resources cooperation. In addition to the business aspect of cooperation project, the framework also highlights the important roles of legal and policy aspects. 


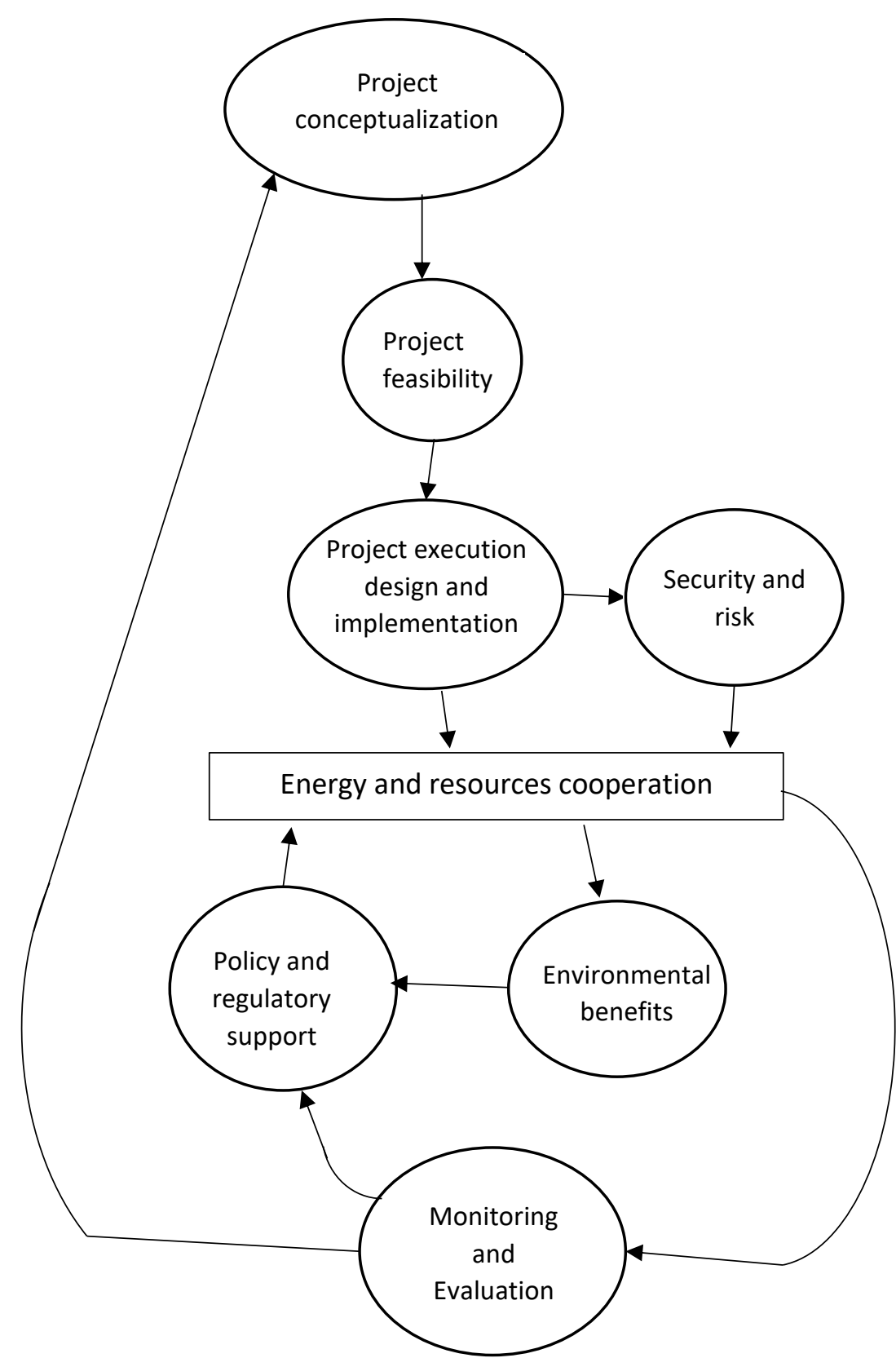

Figure 1: Framework for energy and resources cooperation

A template that systematizes overall methodology for energy and resources cooperation is useful to support establishments of multitude of cooperation projects. Such template is developed in Table 2. Generic steps are shown in the first column and generic activities associated with the steps are shown in second column. It may be noted that the steps 1 through 3 in Table 2 are iterative until a feasible project is found out.

Table 2: Overall methodology for establishing energy and resources cooperation project

\begin{tabular}{|l|c|}
\hline \multicolumn{1}{|c|}{ Steps } & \multicolumn{1}{c|}{ Activities } \\
\hline 1.Stakeholder analysis and mapping & $\begin{array}{r}1.1 \text { Identify companies that could be interested in, } \\
\text { and benefit from cooperation. }\end{array}$ \\
\hline
\end{tabular}




\begin{tabular}{|c|c|}
\hline & $\begin{array}{l}\text { 1.2 Initiate preliminary discussions to: a) } \\
\text { understand willingness to participate in a } \\
\text { potential cooperation project, and b) identify } \\
\text { roles and responsibilities of possible partners. } \\
\text { 1.3 Identify common interfirm interests including } \\
\text { common resources that can be shared. }\end{array}$ \\
\hline 2.Identification of cooperation project & $\begin{array}{l}\text { 2.1 Identify potential resources that could lead to } \\
\text { circular economy or could be shared as } \\
\text { common assets. } \\
\text { 2.2 Identify potential projects for cooperation } \\
\text { based on interests of participating companies. } \\
\text { 2.3 Shortlist potential project(s) based on pre- } \\
\text { feasibility assessment }\end{array}$ \\
\hline 3.Feasibility study of shortlisted project & $\begin{array}{l}\text { 3.1 Conduct detailed feasibility study to: a) ensure } \\
\text { that the project is financially and technically } \\
\text { feasible, b) estimate environmental benefits of } \\
\text { the project. }\end{array}$ \\
\hline $\begin{array}{l}\text { 4.Formulation of project execution } \\
\text { modality }\end{array}$ & $\begin{array}{l}\text { 4.1 Provided that the previous step shows the } \\
\text { project is feasible, determine how the project } \\
\text { will be financed. Similarly, determine how the } \\
\text { profit (if any) from the project will be shared } \\
\text { among partners. } \\
\text { 4.2 Identify resources (including technical skills) } \\
\text { needed to establish the project and determine } \\
\text { who will build infrastructures needed for the } \\
\text { project. } \\
\text { 4.3 Determine roles and responsibilities of all } \\
\text { participating companies. } \\
4.4 \text { Enter into legal contract for assurance and trust } \\
\text { for project development. }\end{array}$ \\
\hline 5.Project execution & $\begin{array}{l}\text { 5.1 Implement the project based on project } \\
\text { execution modality. }\end{array}$ \\
\hline
\end{tabular}

\section{Approach to enhance cooperation}

Lack of trust ${ }^{34,35}$, policy and regulatory, technological, and managerial barriers ${ }^{37}$ have been identified as main obstacles to enhance energy and resources cooperation. This paper proposes establishment of a specialized ESCO to overcome these obstacles as an approach to enhance cooperation. A specialized ESCO, Cooperation Development and Management Company (CDMC), can be developed to support all the phases of energy and resources cooperation shown in cooperation framework (Figure 1). The details of the envisioned CDMC is presented below.

\subsection{Roles and responsibilities of CDMC}

The main role of CDMC is to provide advisory and consultancy service to the companies that participate in energy and resources cooperation project. While the decision-making authority regarding the project may solely remain with the participating companies, the CDMC should provide consultancy services to assist decision making throughout all the phases of energy and resources cooperation shown in Figure 1. Major assistance may be required for project conceptualization, security and risk management, policy, and regulatory support, and monitoring and evaluation support (Figure 1). 
Industrial symbiosis, and energy and resources cooperation in general, has been believed to emerge as a self-organizing complex adaptive system ${ }^{5}$. However, instead of waiting for cooperation to emerge naturally and automatically, initiatives need to be taken to stimulate the establishment of cooperation projects for the mass implementation. Therefore, CDMC should play an active role in project conceptualization. Companies may be interested in participating in energy and resources cooperation, but they may lack time and resources to explore potential cooperation projects and conduct stakeholder analysis and mapping (see step 1 in Table 1). Therefore, CDMC should support these tasks.

Another major area where CDMC can facilitate rapid and mass implementation of cooperation projects is security and risk management. As previously mentioned (Section 3.2.2), trust and security is a major barrier for cooperation and CDMC should provide liaison and legal supports. The liaison support should facilitate communications between participating companies to build trust and reduce the chances of potential misunderstanding. Likewise, legal support should help in preparation of legally binding contracts that assure participating companies that all participants will fulfil their responsibilities or pay sufficient compensation in case of failure to meet their obligations. Furthermore, CDMC could also provide technical support to operationalise and manage cooperation, and optimise interfirm resources sharing through numerical simulations $\mathrm{s}^{39,40}$.

Policy and regulatory support has a major role in mass implementation of energy and cooperation projects, and ten different policy instruments ${ }^{41}$ including industrial guidance, facilitation programme, subsidies, and mass supervisions, have been recommended. CDMC could support these and other relevant policy measures. Finally, CDMC could support in monitoring and evaluation of cooperation projects after they are implemented. This could include assessing a) whether the project is achieving its targeted environmental benefits (e.g. emissions reduction), b) whether the project is operating sustainably (technically, economically and environmentally), c) whether implemented policy or other interventions have worked, and d) lessons learned from the project that can be applied in future.

National Industrial Symbiosis Programme ${ }^{42}$ in UK and Korea Industrial Complex Corporation ${ }^{43}$ in South Korea are some examples of CDMC that have been successfully implemented. These institutions can be made more effective if they take up the roles and responsibilities discussed above. Since each cooperation project can be very unique and type of expertise required can differ in a case by case basis, skills of personnel required in CDMC can be very different for each project. Therefore, rather than hiring many full-time staff with different expertise, the CDMC could hire relevant experts on a project contractual basis. It is recommended that the CDMC create and maintain a roster of experts so that relevant experts can be invited on an as needed basis. However, common experts required for almost every project such as project financial analyst and project development and management officer can be hired on a permanent full-time basis.

Facilitation intermediary companies such as CDMC can often struggle with getting information from firms participating in cooperation projects which has been termed as openness dilemma ${ }^{44}$. Furthermore, CDMC are also often bypassed by participating firms once the firms no longer require support of CDMC to implement the project ${ }^{44}$. Therefore, legally binding agreements or contracts are needed between participating firms and CDMC so that CDMC can get the information it needs and are also kept up-to-date with actions that participating firms take regarding cooperation project. Given that the participating firms may not want certain information to be public for different competition related reasons, they may not be open to information sharing with CDMC. To overcome this problem, CDMC could assure participating firms that information of confidential nature will not be leaked and enter a contractual obligation to not disclose any confidential or sensitive information. 


\subsection{Modality to establish and manage CDMC}

The CDMC is envisioned to assist business aspect of cooperation such as project planning, as well as government aspect such as policy and regulatory support. Since the CDMC supports both private companies and the government, it may be most suitable to establish CDMC as a government entity which allows equity shareholding to private companies. Thus, public private partnership modality is proposed for CDMC establishment and management.

\section{Conclusions and recommendations}

Salient features of energy and resources cooperation are identified by providing its working definition. Realising the potential of such cooperation to reduce negative environmental effects of the industrial sector, a framework to facilitate mass implementation of cooperation projects is proposed along with major generic steps needed to achieve the cooperation. A need to establish a specialized energy service company, termed as Cooperation Development and Management Company in this paper, in order to facilitate mass uptake of cooperation projects is highlighted. Furthermore, this paper initiates a much needed discussion to integrate the disparate areas of industrial ecology, business studies and industrial investments.

Future work is planned to extend the framework and methodology developed in this paper to allow the option of switching cooperation partners, which could optimise the cooperation by helping find companies the best match ${ }^{44,45}$.

Further research on designing and planning of energy and resources cooperation are needed by analysing existing cooperation, several of which are documented in the library of industrial symbiosis ${ }^{46}$. This paper also recommends research agenda of exploring potential applications of peer to peer transaction and industry 4.0 on energy and resources cooperation. Given the potential of peer to peer transaction and industry 4.0 to significantly improve interfirm coordination and information sharing, they could greatly improve trust among participating companies. Furthermore, blockchain enabled peer to peer (P2P) transaction is not bounded by the constraint of geographical proximity of participating companies and can therefore enable cooperation among companies that are located anywhere in the world. Therefore, we call for research on designing effective approaches to utilise $\mathrm{P} 2 \mathrm{P}$ and blockchain to enhance energy and resources cooperation.

\section{Acknowledgement}

This work was supported through European Commission Interreg Two Seas Programme, project titled Port Energy and Carbon Sharing [grant number: PECS 2S03-009].

\section{References}

1. Tollefson J, Global industrial carbon emissions to reach all-time high in 2018. Nature News 2018. DOI: 10.1038/d41586-018-07666-6.

2. Guo Y, Tian J, Zang N, Gao Y, and Chen L. The Role of Industrial Parks in Mitigating Greenhouse Gas Emissions from China. Environ. Sci. Technol. 2018; 52 (14): 7754-7762.

3. IPCC. Climate Change 2014: Mitigation of Climate Change. Contribution of Working Group III to the Fifth Assessment Report of the Intergovernmental Panel on Climate Change [Edenhofer O, PichsMadruga R, Sokona Y, Farahani E, Kadner S, Seyboth K, Adler A, Baum I, Brunner S, Eickemeier P, Kriemann B, Savolainen J, Schlömer S, von Stechow C, Zwickel T and Minx JC (eds.)]. Cambridge University Press 2014, Cambridge, United Kingdom and New York, NY, USA.

4. Heinrichs H. Sharing Economy: A Potential New Pathway to Sustainability. Gaia 2013; 22(4): 228231. 
5. Chertow $M$ and Ehrenfeld J. Organizing Self-Organizing Systems -Toward a Theory of Industrial Symbiosis. Journal of Industrial Ecology 2012; 16 (1): 13-27.

6. Geissdoerfer H, Savaget P, Bocken NMP and Hultink EJ. The Circular Economy-A new sustainability paradigm? Journal of Cleaner Production 2017; 143: 757-768.

7. Baldassarre B, Schepers $\mathrm{M}$, Bocken $\mathrm{N}$ et al. Industrial Symbiosis: towards a design process for ecoindustrial clusters by integrating Circular Economy and Industrial Ecology perspectives. Journal of Cleaner Production 2019; 216: 446- 460.

8. Domenech T, Bleischwitz R, Doranova A, Panayotopoulos D, and Roman L. Mapping Industrial Symbiosis Development in Europe_typologies of networks, characteristics, performance and contribution to the Circular Economy. Resources, Conservation and Recycling 2019; 141: 76-98.

9. Ruggieri A, Braccini AM, Poponi S and Mosconi EM. A Meta-Model of Inter-Organisational Cooperation for the Transition to a Circular Economy. Sustainability 2016; 8 (11).

10. Interreg, 2 Seas Mers Zeeen. Port Energy and Carbon Savings. 2020. Available at: https://www.pecs2seas.eu/.

11. Zhang M, Wang C, Wang S. et al. Assessment of greenhouse gas emissions reduction potential in an industrial park in China. Clean Techn Environ Policy 2020. https://doi.org/10.1007/s10098-02001864-5.

12. Jacobsen NB, Industrial symbiosis in Kalundborg, Denmark: a quantitative assessment of economic and environmental aspects. Journal of industrial ecology 2006, 10(1-2): 239-255.

13. Mirata M. Experiences from early stages of a national industrial symbiosis programme in the UK: determinants and coordination challenges. Journal of Cleaner Production 2004, 12(8-10): 967-983.

14. Zhe L, Yong G, Hung-Suck P, Huijuan D, Liang D, Tsuyoshi F. An emergy-based hybrid method for assessing industrial symbiosis of an industrial park. Journal of Cleaner Production 2016, 114: 132-140.

15. Chertow MR. "Uncovering" industrial symbiosis. Journal of industrial Ecology 2007, 11(1): 11-30.

16. Yu F, Han F, Cui Z. Evolution of industrial symbiosis in an eco-industrial park in China. Journal of Cleaner Production 2015, 87: 339-347.

17. Ramsheva YK, Prosman EJ, Wæhrens BV. Dare to make investments in industrial symbiosis? A conceptual framework and research agenda for developing trust. Journal of cleaner production 2019, 223: 989-997.

18. Ashton WS, Bain AC. Assessing the "short mental distance" in eco-industrial networks. Journal of Industrial Ecology 2012, 16(1): 70-82.

19. Doménech T, Davies M. The role of embeddedness in industrial symbiosis networks: Phases in the evolution of industrial symbiosis networks. Business Strategy and the Environment 2011, 20(5): 281296.

20. Paquin RL, Howard-Grenville J. The evolution of facilitated industrial symbiosis. Journal of industrial Ecology 2012, 16(1): 83-93.

21. Jensen PD, Basson L, Hellawell EE, Bailey MR, Leach M. 2011. Quantifying 'geographic proximity': experiences from the United Kingdom's national industrial symbiosis programme. Resources, Conservation and Recycling 2011, 55(7): 703-712. 
22. Mallawaarachchi H, Sandanayake Y, Karunasena G, Liu C. Unveiling the conceptual development of industrial symbiosis: Bibliometric analysis. Journal of Cleaner Production 2020, 258, https://doi.org/10.1016/i.jclepro.2020.120618.

23. Boons F, Spekkink W, Mouzakitis Y. The dynamics of industrial symbiosis: a proposal for a conceptual framework based upon a comprehensive literature review. Journal of Cleaner Production 2011, 19(9-10): 905-911.

24. Liu Z, Adams M, Cote RP, Geng Y, Ren J, Chen Q, Liu W and Zhu, X. Co-benefits accounting for the implementation of eco-industrial development strategies in the scale of industrial park based on emergy analysis. Renewable and Sustainable Energy Reviews 2018; 81 (1): 1522-1529.

25. Cote RP and Liu C. Strategies for reducing greenhouse gas emissions at an industrial park level: a case study of Debert Air Industrial Park, Nova Scotia. Journal of Cleaner Production 2016; 114: 352361.

26. Chowdhury JI, Hu Y, Haltas I, Balta-Ozkan N, Matthew jr., G and Varga, L. Reducing industrial energy demand in the UK: A review of energy efficiency technologies and energy saving potential in selected sectors. Renewable and Sustainable Energy Reviews 2018; 94: 1153-1178.

27. Giotitsas C, Pazaitis A and Kostakis V. A peer-to-peer approach to energy production. Technology in Society 2015; 42: 28- 38.

28. Dang C, Zhang J, Kwong CP and Li L. Demand Side Load Management for Big Industrial Energy Users under Blockchain-Based Peer-to-Peer Electricity Market. IEEE Transactions on Smart Grid 2019; DOI: 10.1109/TSG.2019.2904629.

29. Sikorski JJ, Haughton J and Kraft M. Blockchain technology in the chemical industry: Machine-tomachine electricity market. Applied Energy 2017; 195: 234-246.

30. Mengelkamp E, Gärttner J, Rock K, Kessler S, Orsini L and Weinhardt C. Designing microgrid energy markets: A case study: The Brooklyn Microgrid. Applied Energy 2018; 210: 870-880.

31. Tushar W, Yuen C, Mohsenian-Rad H, Saha T, Poor HV and Wood KL. Transforming Energy Networks via Peer to Peer Energy Trading: Potential of Game Theoretic Approaches. IEEE Signal Processing Magazine 2018; DOI: 10.1109/MSP.2018.2818327.

32. Xu LD, Xu EL and Li L. Industry 4.0: state of the art and future trends. International Journal of Production Research 2018; 56 (8): 2941-2962.

33. Huang Z, Yu H, Peng Z, Feng Y. Planning community energy system in the industry 4.0 era: Achievements, challenges and a potential solution. Renewable and Sustainable Energy Reviews 2017; 78: $710-721$.

34. Bacudio LR, Benjamin MFD, Eusebio RCP, Holaysan SAK, Promentilla MAB, Yu KDS, Aviso KV. Analyzing barriers to implementing industrial symbiosis networks using DEMATEL. Sustainable Production and Consumption 2016; 7: 57-65.

35. Golev A, Corder GD, Giurco DP. Barriers to Industrial Symbiosis: Insights from the Use of a Maturity Grid. Journal of Industrial Ecology 2014; 19(1). DOI: 10.1111/jiec.12159.

36. Tsvetkova A, Gustafsson M. Business models for industrial ecosystems: a modular approach. Journal of Cleaner Production 2012; 29-30: 246-254. 
37. Galvão GDA, de Nadae J, Clemente DH, Chinen G, de Carvalho MM. Circular Economy: Overview of Barriers. Procedia CIRP 2018; 73: 79-85.

38. Tseng ML, Tan RR, Chiu AS, Chien CF, Kuo TC. Circular economy meets industry 4.0: Can big data drive industrial symbiosis? Resources, Conservation and Recycling 2018, 131: 146-147.

39. Freitag M, Becker T, Duffie NA. Dynamics of resource sharing in production networks. CIRP Annals 2015; 64 (1): 435-438.

40. Yazan DM, Fraccascia L. Sustainable operations of industrial symbiosis: an enterprise input-output model integrated by agent-based simulation. International Journal of Production Research 2020; 58 (2): 392-414.

41. Tao Y, Evans S, Wen Z, Ma M. The influence of policy on industrial symbiosis from the Firm's perspective: A framework. Journal of Cleaner Production 2019; 213: 1172-1187.

42. International Synergies. National Industrial Symbiosis Programme. 2020. Available at: https://www.international-synergies.com/projects/national-industrial-symbiosis-programme/.

43. European Cluster Collaboration Programme. The Catalan cluster experience presented at the Korean cluster day 2018. Available at: https://www.clustercollaboration.eu/news/catalan-clusterexperience-presented-korean-cluster-day-2018.

44. Patala S, Salmi A, Bocken N. Intermediation dilemmas in facilitated industrial symbiosis. Journal of Cleaner Production 2020; 261.

45. Hampl N. Drivers of and barriers to partner switch in interfirm alliances: a conceptual model. Journal of Business Economics 2019; https://doi.org/10.1007/s11573-019-00965-y.

46. Evans S, Benedetti M, Holgado MG. Library of Industrial Symbiosis case studies and linked exchanges. 2017 [Dataset]. https://doi.org/10.17863/CAM.12608. 